\title{
OPTIMALISASI TUMBUH KEMBANG BALITA MELALUI PROMOSI GIZI SEIMBANG DI KECAMATAN KOTO TANGAH PADANG
}

\section{OPTIMIZATION OF GROWTH TALK THROUGH BALANCED NUTRITION PROMOTION IN KOTO TANGAH PADANG}

\section{Azrimaidaliza $^{1)^{*}}$, Annisa ${ }^{2)}$, Yasirly Khairany ${ }^{3)}$, Nurul Prativa ${ }^{4)}$, Rahmani Adrianus ${ }^{5)}$, Mesa Putri Salmah'}

${ }^{1)}$ Fakultas Kesehatan Masyarakat, Universitas Andalas, email: azrimaidaliza@ph.unand.ac.id

${ }^{2)}$ Fakultas Kesehatan Masyarakat, Universitas Andalas, email: annisa.giziunand@ gmail.com

${ }^{3)}$ Fakultas Kesehatan Masyarakat, Universitas Andalas, email: yasirlykhirany.20@ gmail.com

5)

Fakultas Kesehatan Masyarakat, Universitas Andalas, email : nurulprativa7@ gmail.com

Fakultas Kesehatan Masyarakat, Universitas Andalas, email : rahmania.adrianus@yahoo.com

${ }^{6)}$ Fakultas Kesehatan Masyarakat, Universitas Andalas, email : smesaptr@gmail.com

\begin{abstract}
ABSTRAK
Masa balita merupakan masa yang dikenal sebagai golden age dan periode kritis. Dimana, Golden age ini merupakan masa yang sangat penting untuk memperhatikan tumbuh kembang anak secara cermat agar sedini mungkin dapat terdeteksi apabila terjadi kelainan. Pemberian asupan gizi yang sesuai untuk tumbuh kembang secara optimal juga perlu diperhatikan, karena jika asupan gizi tidak terpenuhi sesuai kebutuhannya, golden age akan menjadi periode kritis yang akan mengganggu proses tumbuh kembang anak. Mengingat gizi merupakan faktor penting dalam pola pertumbuhan dan perkembangan anak pada masa golden age, maka memperhatikan kebutuhan dan porsi pemberian gizi seimbang menjadi wajib bagi orang tua. Promosi gizi merupakan salah satu bentuk kegiatan komunikasi informasi dan edukasi yang dapat meningkatkan pengetahuan gizi ibu,penanaman sikap ibu yang poitif terhdap gizi seimbang serta adanya perbaiakn pada pola makan dalam keluarga terkhusus pada balita. Pengabdian masyarakat ini melakukan promosi gizi melalui penyuluhan berupa penyampaian materi terutama mengenai pentingnya gizi seimbang pada masa golden age yang disertai dengan pemberian leafleat dan demo dengan saran yaitu ibu yang memiliki balita di Puskesms Anak Air dan Puskesmas Air Dingin. Kegiatan penyuluhan ini diawali dengan pre-test untuk mengetahui pengetahuan dan sikap ibu mengenai gizi seimbang, kegiatan penilaian status gizi melalui pengukuran berat dan panjang badan. Kegiatan penyampaian materi oleh pengabdi yang diakhiri dengan kegiatan posttest. Tujuan pemberian pre test dan post test adalah untuk mengetahui apakah terdapat peningkatan pengetahuan dan sikap ibu yang memiliki balita setelah dilakukannya kegiatan penyuluhan. Kegiatan penyuluhan dilakukan 1 kali per puskesmas pada selang waktu kegiatan posyandu di Puskesmas Air Dingin dan Puskesmas Anak Air.
\end{abstract}

Kata Kunci : Balita, Golden Age, Gizi Seimbang

\section{ABSTRACT}

Toddler period is a period known as the golden age and critical period. This golden age is a very important time to pay close attention to the child's growth and development so that as early as possible can be detected if abnormalities occur. Providing appropriate nutritional intake for optimal growth and development also needs to be considered, because if the nutritional intake is 
not met according to their needs, the golden age will be a critical period that will interfere with the child's growth and development process. Considering nutrition is an important factor in the pattern of growth and development of children during the golden age, then paying attention to the needs and portions of balanced nutrition is mandatory for parents. Nutrition promotion is a form of information and education communication activities that can increase the mother's nutritional knowledge, the inculcation of positive maternal attitudes towards balanced nutrition and the improvement of dietary patterns in the family especially in infants. This community service is promoting nutrition through counseling in the form of delivering material, especially on the importance of balanced nutrition during the golden age accompanied by the provision of leafleat and demonstrations with advice, namely mothers who have children under five in the Water Children Health Centre and Cold Water Health Centre. This counseling activity begins with a pre-test to find out knowledge and attitudes of mothers regarding balanced nutrition, nutritional status assessment activities through weight and length measurements. Submission of services by the servants, which ended with a post-test activities. The purpose of giving pre-test and post-test is to find out whether there is an increase in knowledge and attitudes of mothers who have children under five years after counseling activities. Counseling activities are carried out once per health centre at the interval of Posyandu activities at Air Dingin health centre and Anak Air health centre.

Keywords: Children under five years, Golden age, Balanced nutrition,

\section{PENDAHULUAN}

Pertumbuhan dan perkembangan mengalami peningkatan yang sangat pesat dan menakjubkan pada usia dini, yaitu dari 0 sampai 5 tahun [1]. Masa ini dikenal sebagai golden age dan periode kritis. Golden age merupakan masa yang sangat penting untuk memperhatikan tumbuh kembang anak secara cermat agar sedini mungkin dapat terdeteksi apabila terjadi kelainan [2]. Pemberian asupan gizi yang sesuai untuk tumbuh kembang secara optimal juga perlu diperhatikan, karena jika asupan gizi tidak terpenuhi sesuai kebutuhannya, golden age akan menjadi periode kritis yang akan mengganggu proses tumbuh kembang anak [3].

Asupan makanan yang bergizi sangat penting bagi pertumbuhan sel otak dan fisik anak saat balita. Apabila anak mengalami kekurangan gizi akan berdampak pada terganggunya pertumbuhan, rentan terhadap infeksi, peradangan kulit, ketidakmampuan berprestasi, produktifitas yang rendah dan akhirnya dapat menghambat perkembangan anak meliputi kognitif, motorik, bahasa, dan keterampilannya dibandingkan dengan anak yang memiliki status gizi baik [1]. Mengingat gizi merupakan faktor penting dalam pola pertumbuhan dan perkembangan anak pada masa golden age, maka memperhatikan kebutuhan dan porsi pemberian gizi seimbang menjadi wajib bagi orang tua.

Kurangnya pengetahuan ibu tentang gizi akan mengakibatkan berkurangnya kemampuan untuk menerapkan informasi dalam kehidupan sehari-hari yang merupakan salah satu penyebab terjadinya gangguan gizi [4]. Adapun tujuan dari promosi gizi adalah: a) 
untuk membentuk sikap positif terhadap gizi;

b) menambah pengetahuan tentang gizi; c) menimbulkan motivasi untuk mengetahui lebih lanjut tentang hal-hal yang berkaitan dengan gizi; d) agar terjadinya perubahan perilaku yang lebih baik untuk mengoptimalkan masa golden age anak [5].

Dilihat dari hasil Riset Kesehatan Dasar (Riskesdas) Tahun 2018, Indonesia mengalami angka penurunan gizi buruk dan gizi kurang pada balita sejak tahun 2013, yaitu 19,6\% menjadi $17,7 \%$ (gizi buruk 3,9\% dan gizi kurang 13,8\%) [6], [7]. Namun angka penurunan tersebut belum mencapai target RPJMN yaitu 17\%. Pada tahun 2018 kasus gizi buruk tertinggi berada di Kota Padang dengan prevalensi 16,34\%, untuk kasus BGM di kota Padang prevalensinya $1,15 \%$ dan Puskesmas dengan kasus BGM tertinggi terdapat di wilayah kerja Puskesmas Air Dingin 4,55\% diikuti dengan Puskesmas Anak Air 5,51\%. Keadaan BGM yang tinggi di Puskesmas Air Dingin dan Puskesmas Anak Air memerlukan pemantauan agar balita yang BGM tidak jatuh kedalam kondisi gizi buruk.

Hasil penelitian Milda dan Ratnawati di wilayah kerja Puskesmas Gapura Kabupaten Sumenep, Jawa Timur Tahun 2018 menyatakan bahwa terdapat hubungan antara pengetahuan ibu dengan status gizi balita [8]. Kemudian didukung oleh penelitian Hantari tahun 2017 yang menunjukkan bahwa kurangnya pengetahuan ibu tentang gizi akan mengakibatkan berkurangnya kemampuan untuk menerapkan informasi dalam kehidupan sehari-hari yang merupakan salah satu penyebab terjadinya gangguan gizi pada anak [4]. Hasil studi Azrimaidaliza (2019) mendapatkan separuh ibu-ibu yang tinggal di Puskesmas Air Dingin dan Puskesmas Anak Air memiliki pengetahuan gizi kurang (54.2\%), Oleh karena itu diperlukan peningkatan pengetahuan ibu tentang gizi seimbang untuk optimalisasi tumbuh kembang anak terutama usia di bawah lima tahun.

\section{METODE}

Kegiatan pengabdian dilaksanakan bersamaan dengan jadwal kegiatan Posyandu di Puskesmas. Kegiatan pengabdian kepada masyarakat yaitu berupa kegiatan Komunikasi Informasi dan Edukasi (KIE) dengan tahapan

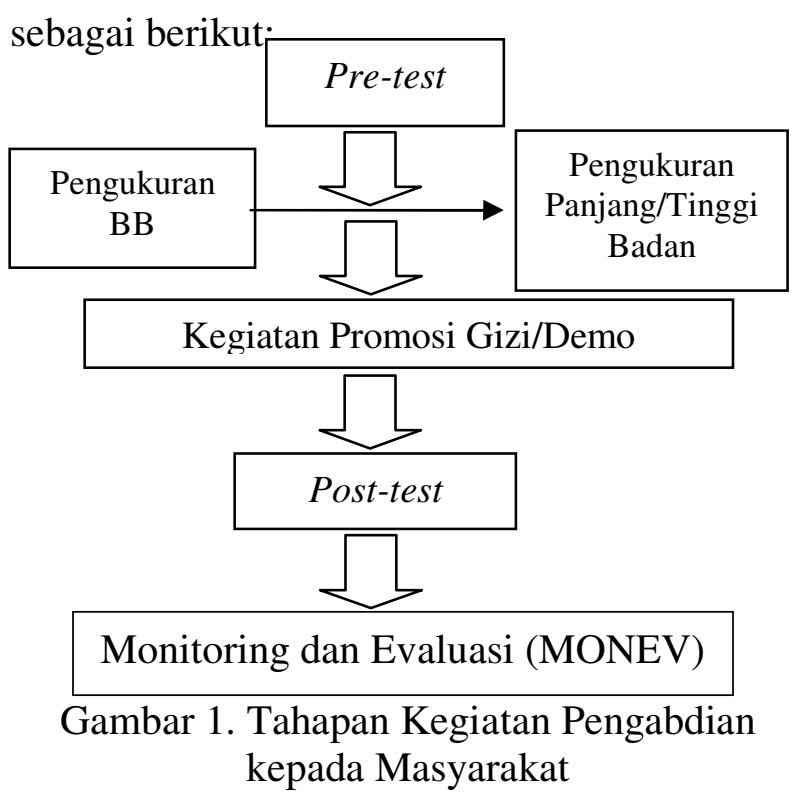


Kegiatan pengabdian kepada masyarakat dilaksanakan di Puskesmas Anak Air dan Puskesmas Air Dingin. Pengabdian ini diharapkan sebahagian besar ibu yang mempunyai balita memperoleh informasi mengenai pentingnya gizi seimbang yang kemudian dapat menyampaikan kepada masyarakat maupun keluarga lainnya serta menerapkan dalam kehidupan sehari-hari untuk mengoptimlkan tumbuh kembang balita.

Kegiatan pengabdian kepada masyarakat dilaksanakan dengan mempersiapkan materi penyuluhan, antara lain; (1) pentingnya masa golden age, (2) pengertian gizi seimbang, (3) pesan umum gizi seimbang, dan (4) pesan gizi seimbang untuk anak usia 2-4 tahun. Media pendukung kegiatan penyuluhan berupa leafleat yang memuat tentang materi disiapkan dan media pendukung lainnya.

\section{HASIL DAN PEMBAHASAN}

Puskesmas Air Dingin terletak di Kecamatan Koto Tangah. luas wilayah kerja 144,91 Km2 , dengan topografi berupa dataran dan perbukitan yang merupakan daerah pertanian dan perkebunan pengembangan kota baru. Sejak tahun 2012 ini wilayah kerja Puskesmas Air Dingin menjadi 3 Kelurahan yaitu Kelurahan Balai Gadang, Kelurahan Lubuk Minturun dan Kelurahan Air Pacah. Tenaga kesehatan yang bertugas di Puskesmas Anak Air berjumlah sebanyak 61 orang yaitu
47 orang PNS, 3 orang PTT, dan 11 orang tenaga sukarela. Sarana dan prasarana yang tersedia di Puskesmas Air Dingin antara lain adalah 1 Puskesmas induk, 3 Puskesmas Pembantu, 1 Poliklinik, 1 gedung UGD, 1 klinik rawatan, 2 kendaraan roda dua dan 1 kendaraan roda empat.

Puskesmas Anak Air awalnya merupakan puskesmas pembantu Air Dingi yang kemudian pada tahun 2012 berubah fungsi menjadi puskesmas Anak Air sebagai Unit Pelayanan Teknis Dinas Kesehatan Kota Padang yang disahkan dengan Surat Keputusan Walikota Padang Nomor 256 Tahun 2011. Puskesmas Anak air terletak di Kelurahan Batipuh Panjang Kecamatan Koto Tangah Kota Padang dengan luas $2754 \mathrm{Km}^{2}$. Puskesmas Anak Air mempunyai tenaga kesehatan yang bertugas di dalam gedung induk dan puskesmas pembantu sebanyak 31 orang PNS, PTT 5 orang dan 5 orang tenaga sukarela. Untuk membantu kegiatan di wilayah Puskesmas Anak Air memiliki 1 Puskesmas Pembantu/ Poskeskel di Padang Sarai dan 1 Puskesmas Pembantu/ Poskeskel di Batipuh Panjang.

Kegiatan pengabdian kepada masyarakat berupa " Optimalisasi Tumbuh Kembang balita Melalui Promosi Gizi Seimbang Di Kecamatan Koto Tangah Kota Padang Tahun 2019” yang dilaksanakan pada hari Rabu tanggal 7 Jagustus 2019 di Puskesmas Anak air dan hari 
Rabu tanggal 11 Setember 2019 yang berlokasi di Puskesmas Air Dingin. Kegiatan yang dilakukan, sebagai berikut

1. Persiapan sebelum kegiatan, meliputi;

a. Pengurusan izin untuk kegiatan pengabdian kepada masyarakat ke Dinas Kesehatan Kota Padang (surat keterangan kegiatan terlampir).

b. Pembuatan leafleat yang memuat materi yang disampaikan kepada sasaran.

c. Penyusunan kuesioner pre-test dan posttest untuk mengetahui tingkat pengetahuan ibu tentang oentingnya gizi seimbang untuk tumbuh kembang anak (kuesioner terlampir).

d. Pembuatan spanduk untuk kegiatan (terlampir).

e. Koordinasi dengan tenaga kesehatan khusunya pemegang program gizi di Puskesmas Air Dingin dan Puskesmas Anak Air untuk mengizinkan anggota ibu balita yang mengikuti posyandu mengikuti kegiatan.

2. Pelaksanaan kegiatan "Optimalisasi Tumbuh Kembang balita melalui Promosi Gizi Seimbang di Kecamatan Koto Tangah Kota Padang Tahun 2019” sebagai berikut;

a. Kegiatan diikuti oleh; 52 orang yang terdiri dari 27 orang di Puskesmas Anak Air dan 25 orang di Puskesmas Air Dingin. b. Kegiatan diawali dengan penjelasan kepada ibu-ibu yang mengikuti posyandu mengenai kegiatan pengabdian masyarakat yang akan dilakukan. Hal ini disampaikan oleh pemateri/penyuluh dibantu oleh bidan dan petugas pemegang program gizi

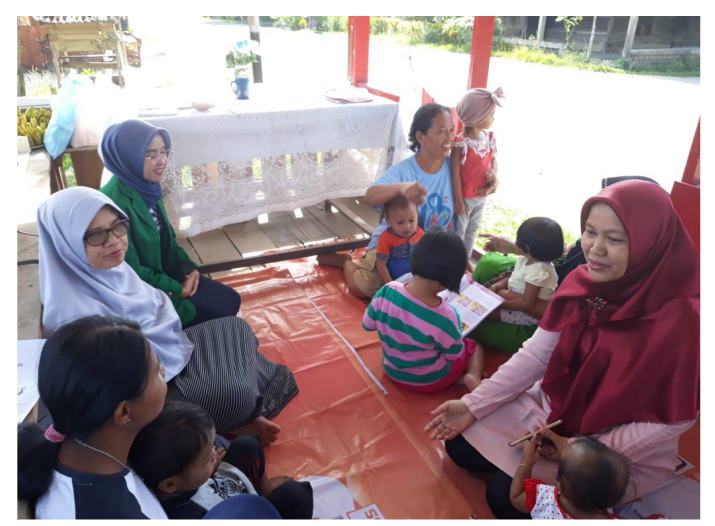

Gambar 2. Penjelasan kegiatan Pengabdian kepada Masyarakat yang akan dilakukan

c. Kegiatan Kegiatan pre-test dilakukan Kegiatan pre-test dilakukan sebelum disampaikannya materi tentang “ Optimalisasi Tumbuh Kembang balita Melalui Promosi Gizi Seimbang Di Kecamatan Koto Tangah Kota Padang Tahun 2019”. anggota posyandu diminta untuk menjawab beberapa pertanyaan (kuesioner) yang terkait dengan materi yang akan disampaikan 


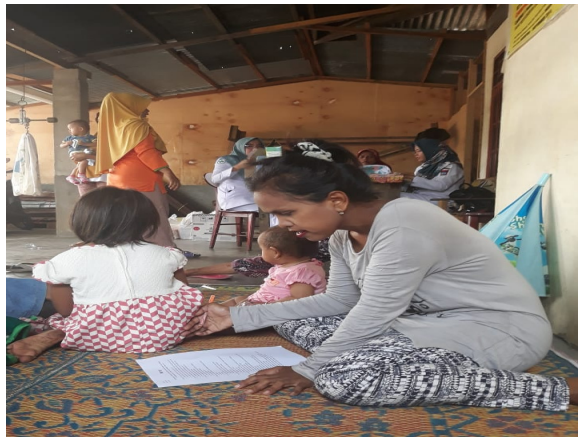

Gambar 3. Kegiatan Pre-test

sebelum penyampaian materi penyuluhan

d. Penyampaian materi oleh

Penyuluh/pemateri dengan menggunakan metoda ceramah menggunakan media leaflet. Leaflet dibagikan kepada anggota posyandu pada saat penyuluhan dan leaflet dikumpulkan kembali pada saat kegiatan post-test. Setelah penyampaian materi, anggota posyandu diberi kesempatan untuk mengajukan pertanyaan. anggota posyandu yang hadir dalam kegiatan ini cukup antusias dan semangat dengan materi yang disampaikan. Hal ini terlihat dari pertanyaan-pertanyaan yang diajukan.
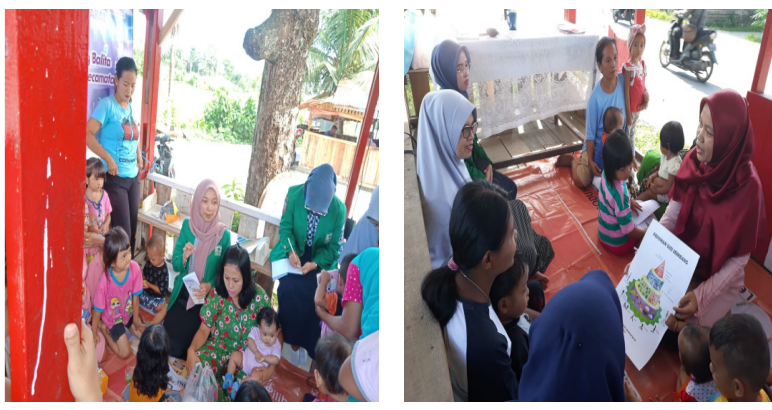

Gambar 4. Penyampaian materi oleh pengabdi

e. Penilaian status gizi balita melalui pengukuran/penimbangan berat badan dan panjang atau tinggi badan.

Penimbangan berat badan menggunakan timbangan digital dan untuk panjang badan menggunakan alat pengukur panjang badan bagi balita yang berusia dibawah 2 tahun atau yang belum bisa berdiri lurus/tegap.
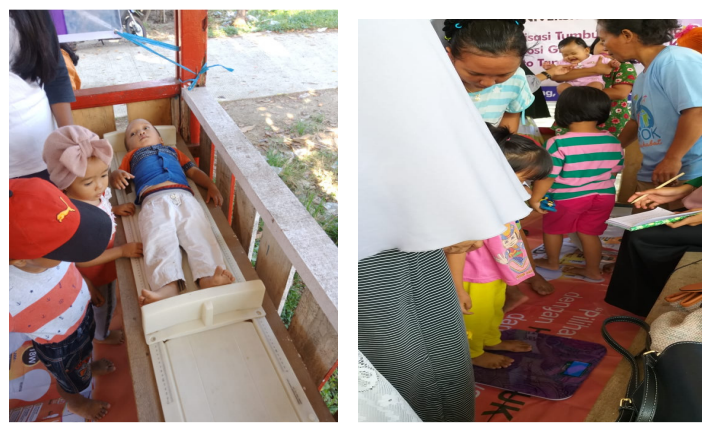

Gambar 5. Pengukuran Panjang Badan dan Berat Badan Balita

Gambaran karakteristik balita berdasarkan umur dan jenis kelamin yang ikut posyandu dan ikut kegiatan pengabdian dapat dilihat pada Tabel 1 berikut;

Tabel 1. Gambaran Karakteristik Balita menurut Jenis Kelamin dan Umur

\begin{tabular}{lcc}
\hline Karakteristik & \multicolumn{2}{c}{ Jumlah } \\
\cline { 2 - 3 } balita & f & $\%$ \\
\hline Jenis Kelamin & & \\
Laki-laki & 19 & 36,5 \\
Perempuan & 33 & 63,5 \\
Umur & & \\
$0-11$ & 9 & 17,31 \\
$12-23$ & 7 & 13,46 \\
$24-35$ & 22 & 42,31 \\
$36-47$ & 5 & 9,62
\end{tabular}




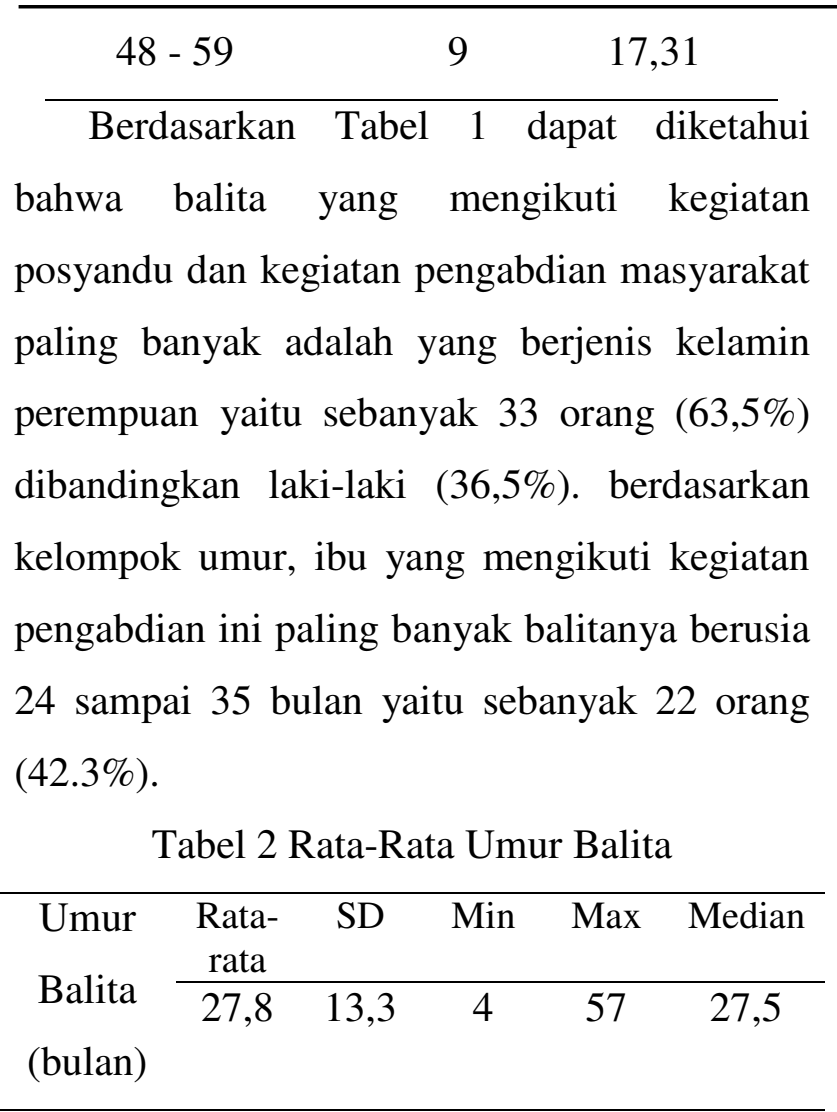

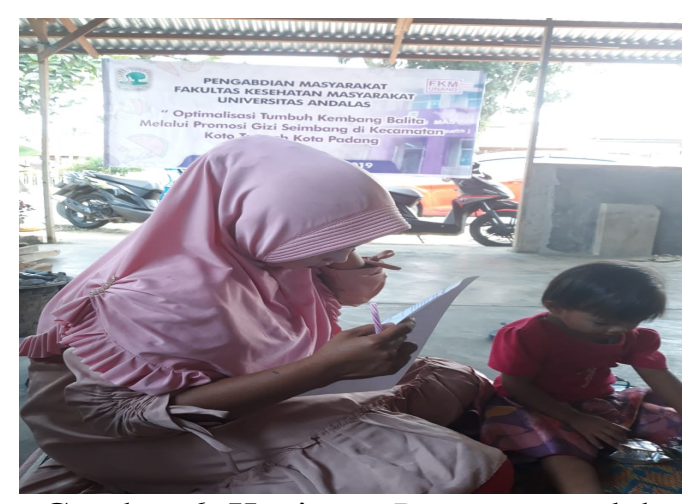

Gambar 6. Kegiatan Post-test setelah penyampaian materi penyuluhan

Tingkat pengetahuan gizi ibu ibu balita yang ikut dalam kegiatan pengabdian dapat diketahui melalui pertanyaan yang diajukan, yaitu sebanyak 10 pertanyaan mengenai pola hidup sehat. dan gizi seimbang. Pengetahuan gizi ibu ini dikelompokkan menjadi 2 kategori, yaitu pengetahuan baik dan pengetahuan kurang. Pengetahuan baik apabila ibu dapat menjawab pertanyaan betul sebanyak $\geq 7$ pertanyaan dan pengetahuan kurang apabila ibu menjawab pertanyaan betul sebanyak $<7$ pertanyaan. Hasil kegiatan pre-test dan posttest menunjukkan tingkat pengetahuan gizi seimbang ibu-ibu balita, dengan hasil sebagai berikut (Gambar 1);

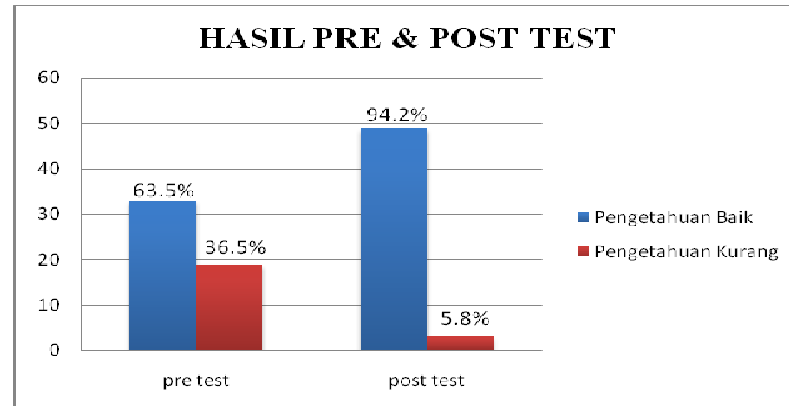

Grafik 1 Tingkat Pengetahuan Ibu Balita berdasarkan kegiatan Pre-test dan Post-test pada Kegiatan Pengabdian Kepada Masyarakat Tahun 2019 


\begin{abstract}
Berdasarkan Grafik 1 dapat diketahui bahwa terdapat peningkatan pengetahuan gizi ibu balita saat melakukan kegiatan Pre-test dan Post-test. Tingkat pengetahuan ibu dengan kategori baik saat pre test ialah sebanyak 33 orang (63.5\%), sedangkan pada saat Post-test meningkat menjadi 49 orang $(94.2 \%)$ yang memiliki tingkat pengetahuan baik.
\end{abstract}

Pengetahuan gizi ibu yang baik diharapkan dapat meningkatkan penerapan asuhan terkhusus asuhan makan yang sesuai dengan gizi seimbang sehingga terpenuhi kebutuhan anak yang akan mendukung terhadap pertumbuhan dan perkembangan anak. Berbagai teori dan penelitian sudah membuktikan bahwa pengetahuan ibu yang kurang baik merupakan salah satu faktor yang dapat menimbulkan permasalahan gizi dan kesehatan pada balita.

g. Kegiatan pengabdian kepada kelompok sasaran yaitu ibu-ibu balita ditutup dengan kegiatan foto bersama dengan kader Posyandu yang juga sudah membantu kegiatan pengabdian ini.

Gambaran berat badan dan tinggi badan balita yang mengikuti kegiatan pengabdian kepada masyarakat dapat dilihat pada tabel berikut;

Tabel 3 Rata-rata Pengukuran Panjang/Tinggi Badan dan Berat Badan Balita

\begin{tabular}{|c|c|c|c|c|}
\hline Pengukuran & $\begin{array}{c}\text { Rata- } \\
\text { rata }\end{array}$ & SD & Min & max \\
\hline
\end{tabular}

\begin{tabular}{|c|c|c|c|c|}
\hline BB & 12.2 & 10.54 & 6 & 16 \\
\hline TB & 86 & 10.45 & 66 & 105 \\
\hline
\end{tabular}

Berdasarkan Tabel 3 dapat diketahui bahwa rata-rata Berat Badan (BB) balita yang mengikuti kegiatan pengabdian adalah $12,2 \mathrm{~kg}$, dan rata-rata Tinggi atau Panjang Badan balita adalah $86 \mathrm{~cm}$.

Kegiatan pengabdian kepada masyarakat seperti yang dilakukan oleh pengabdi melalui kerjasama antar institusi kesehatan, salah satunya dengan Dinas Kesehatan Kota Padang dan Puskesmas merupakan salah satu upaya yang dapat dilakukan untuk meningkatkan pengetahuan masyarakat, terkhusus para ibu mengenai gizi seimbang untuk tumbuh kembang balita. Pemahaman tentang pola hidup sehat dan gizi seimbang melalui kegiatan promosi gizi diharapkan lebih efektif sehingga meningkatkan pengetahuan, sikap, dan perilaku ibu dalam menerapkan pola hidup sehat dan gizi seimbang pada balita.

Kegiatan pengabdian ini berupa promosi gizi terkait gizi seimbang sesuai dengan yang direncanakan yaitu sebanyak 2 kali di 2 lokasi dengan tujuan agar dapat mencakup sasaran yang lebih luas dan lebih banyak. Kegiatan ini diharapkan tidak hanya terfokus pada ibu balita yang berkunjung ke posyandu dan ikut penyuluhan saja tetapi tetapi juga hendaknya ibu -ibu balita tersebut juga dapat menyampaikan kepada keluarga, ibu-ibu yang 
tinggal di sekitar rumah ibu serta dapat menerapkannya dalam kehidupan sehari-hari.

Beberapa keterbatasan yang ditemukan dalam kegiatan pengabdian antara lain; mencari waktu yang tepat dalam mengadakan kegiatan karena kegiatan ini diselipkan pada kegiatan Posyandu di Puskesmas. Kemudian di satu sisi mengumpulkan sejumlah sasaran agar bisa tenang dan serius dalam mengikuti kegiatan merupakan tantangan tersendiri bagi pengabdi dan anggota pengabdi mengingat jumlah yang berkunjung di Posyandu cukup banyak serta tempat yang kurang memungkinkan untuk bisa berinteraksi dan berkomunikasi lebih baik, disamping tidak semua sasaran yang bersedia mengikuti kegiatan sampai selesai.

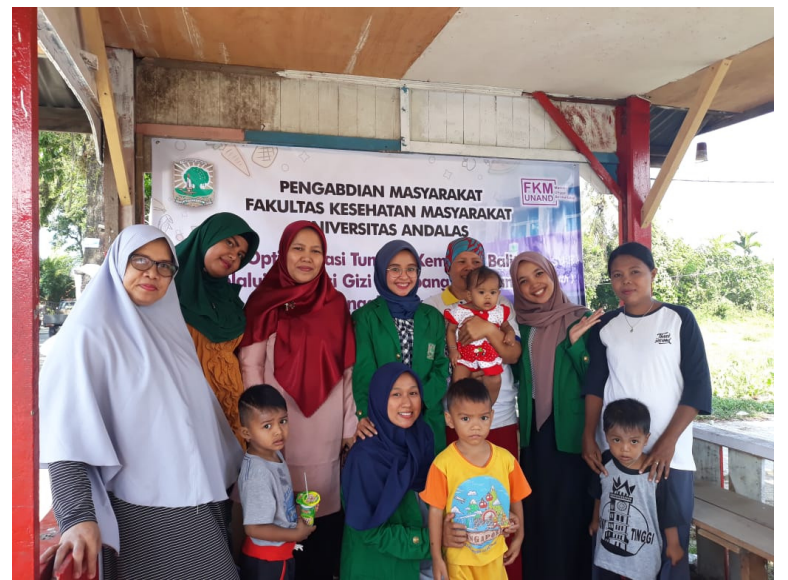

Gambar 9. Pengabdi bersama Ibu Balita dan petugas kesehatan Puskesmas

Secara umum kegiatan pengabdian ini berjalan dengan lancar dan dapat mencapai tujuan ataupun target dari pengabdi. Hal ini terlihat dari adanya peningkatan persentase pengetahuan ibu tentang gizi seimbang setelah diberikannya penyuluhan. Hasil yang lebih baik tentunya bisa diperoleh apabila penyuluhan dilakukan secara kontinyu.

Kedepannya, kegiatan pengabdian ini dapat dilakukan secara rutin dan tidak hanya dilakukan pada dua Puskesmas saja, tetapi dapat dilakukan di Puskesmas lainnya. Ibu-ibu yang terlibat dalam kegiatan ini diharapkan jumlahnya lebih banyak dengan metoda yang lebih baik dan suasana yang lebih mendukung, lebih tenang selama kegiatan berlangsung sehingga pengabdi dapat memberikan kontribusi yang lebih baik dalam upaya optimalisasi tumbuh kembang balita.

\section{KESIMPULAN}

1. kegiatan pengabdian masyarakat yang dilaksanakan di Puskemsas Air dingin dan Anak air secra umum berjalan dengan lancer sesuai dengan yang dirncanakan

2. Kegiatan ini terdiri dari beberapa tahapan yaitu Pre-Test, Penyuluhan atau penyampaian materi terkait gizi seimbang, Post-test, dan pengukuran berat badan dan panjang atau tinggi badan.

3. Ibu ibu peserta dalam pengbdian ini antusias dengan kegiatan yang dilaksanakan dibuktikan dengan kehadiran dan keseriusannya dalam mendengarkan materi yang disampaikan. Beberapa ibu balita juga memebrikan pertanyaan terkait beberapa 
4. materi yang disampaikan dan keluhan dalam penerapan kehidupan sehari-hari.

5. Hasil kegiatan yang sudah dilakukan menggambarkan bahwa adanya peningkatan pengetahuan dan informasi mengenai gizi seimbang dan diharapkan dapat diterapkan dalam kehidupan sehari hari yang selanjutnya akan memberikan dampak baik bagi tumbuh kembang anak mereka

\section{DAFTAR PUSTAKA}

[1] Chamidah AN. Pentingnya Stimulasi Dini Bagi Tumbuh Kembang Otak Anak. Unit Pelayanan Kesehatan UNY. 2009;

[2] Sit M. Psikologi Perkembangan Anak Usia Dini Jilid I. Perdana Publishing; 2015.

[3] Uce L. The Golden Age: Masa Efektif Merancang Kualitas Anak. Hist Mech
Mach Sci. 2017;

[4] Hantari ARF. Upaya Peningkatan Pengetahuan Tentang Nutrisi Usia Prasekolah pada Ibu dengan Anak Status Gizi Kurang. Muhammadiyah Surakarta; 2017.

[5] Mardalena I. Dasar-dasar Ilmu Gizi Dalam Keperawatan. Pustaka Baru Press. 2017. 147-157 hal.

[6] Riskesdas 2013. RISKESDAS, 2013. Lap Nas 2013. 2013;1-384Riskesdas, 2013. (2013). RISKESDAS, 2013. Lap.

[7] Kementerian Kesehatan RI. Hasil Riset Kesehatan Dasar (RISKESDAS) 2018. Has utama Riskesdas 2018. 2018;1-220.

[8] Nirmala Sari MR, Ratnawati LY. Hubungan Pengetahuan Ibu tentang Pola Pemberian Makan dengan Status Gizi Balita di Wilayah Kerja Puskesmas Gapura Kabupaten Sumenep. Amerta Nutr. 2018;2(2):182. 